\title{
Vertebral Body Changes in the Lower Spine of Basketball Players
}

\author{
Mansoorehossadat Rozan ${ }^{1 *}$, Vahid Rouhollahi ${ }^{2}$, Dilip Kumar Dureha ${ }^{1}$ and Amit Rastogi $^{3}$ \\ ${ }^{1}$ Department of Physical Education, Banaras Hindu University, India \\ ${ }^{2}$ Faculty of Physical Education, Shahid Bahonar University of Kerman, Iran \\ ${ }^{3}$ Department of Orthopedics, Banaras Hindu University, India
}

Submission: July 16, 2018; Published: July 25, 2018

*Corresponding author: Mansoorehossadat Rozan, Department of Physical Education, Banaras Hindu University, Varanasi (221005), Uttar Pradesh, India, Phone: +919838434439; Email: rozan.mansoore@gmail.com

\begin{abstract}
Professional sport activities or work may exert considerable stress on the spine. We aimed to assess the effects of loading on the deformation of the vertebral body of the twelfth thoracic vertebra (T12) and the lumbar vertebrae (L1-L5), which are subjected to considerable stress in basketball players. A total of 20 basketball players were assigned to one of two groups, based on their experience with playing basketball: under 5 years, junior group; over 5 years, senior group. All participants underwent magnetic resonance imaging; the relevant geometric variables were measured using specialized software, and the outcome measures were calculated using specific formulas; the outcome measures were compared between the junior and senior groups. The results indicated a significant difference between the two groups with respect to the compression deformity ratio at four levels (T12, L1, L2, and L3), and to the biconcave deformity at one level (L3). Our data suggest that the mechanical loading on lower spine plays an important role in the development of degenerative changes of the vertebral body, which may be considered a risk factor for future injury and low back pain in basketball players.
\end{abstract}

Keywords: Vertebral body changes; Magnetic resonance imaging; Basketball

Abbreviations: T12: Thoracic Vertebra; L1-L5: Lumbar Vertebrae; Ha: Anterior Margin; Hp: Posterior Margin; Hm: Halfway Between these Margins; Dap: Anterior-Posterior Diameter; BMI: Body Mass Index

\section{Introduction}

During sports activities, several important musculoskeletal structures are required to perform complex spinal movement patterns that involve bending and twisting at high speeds. Therefore, the spine is subject to the action of many forces, due to both physiological motion (flexion, extension, rotation, lateral flexion) and accessory motion (shearing tension, compression) [1]. Depending on the direction, magnitude, and point of application of the forces, the spine may suffer deformation and injury. Abnormalities of the spine may also cause injury and pain among athletes because of the unique demands related to each specific sports activity. Lumbar spine injuries represent a significant concern to the athletes, coaches, and physicians.

During athletic endeavors, the lumbar spine is subjected to considerable stress due to unfavorable biomechanical situations typically occurring during such activities [2]. The thoracolumbar and lumbar spine are particularly susceptible to injury due to the large forces exerted in these regions, which are related to: body weight; loads created by motions such as flexion, extension, and rotation [3]; and loads created by accelerating motions especially in sports demanding high speed movements.

In athletes, independent variables that contribute, individually or in combination, to lumbar spine injury include poor technique, poor conditioning, and abnormal anatomy; thus, young athletes may have a spinal deformity that is incidentally or potentially related to their sports activities [4].

Heavy physical work can lead to degenerative changes in the spine [5,6], with body position being a factor that can dramatically affect the load on the lumbar spine. It was shown that the vertebral body undergoes a gradual change in shape under the application of a constant load [7]. Compressive damage arising from repetitive loading is most likely a common event in life; damage to the vertebral body causes decompression of the adjacent disc, leading to internal disc disruption and further degenerative changes [8-10]. Compression fractures can occur 
with axial loading in a flexed or vertical position. The capacity of the spine to resist injury is decreased if the forces applied involve flexion and are of long duration [11].

It has been demonstrated that the load on the spine during physical activity can be measured based on changes in stature [12]. In analyses of force transmission and in model studies on the spine in high level athletes, it is necessary to estimate reference geometric parameters. It is particularly important to determine the size of the intervertebral discs, the size and shape of the vertebrae, and the overall shape of the spine [13].

Besides the loads carried or lifted by the upper extremities, loads caused by specific, frequent movement during sports activities cause significant loading stress to the vertebral bodies, inducing continuous remodeling of the vertebrae. This leads to degeneration and deformities of the vertebral body, which is associated with increased risk of injury. In the case of the lumbar spine, loads due to flexion, extension, rotation, and acceleration are typically associated with deformity of the vertebral body.

To assess the potential deformation, the height of the vertebral body is measured in three places: at the anterior margin ( $\mathrm{Ha})$, at the posterior margin ( $\mathrm{Hp}$ ), and at halfway between these margins (Hm). Three types of vertebral deformities can then be defined based on these heights and on the anterior-posterior diameter (Dap) of the vertebral body. Thus, an anterior wedge deformity is characterized by a low $\mathrm{Ha} / \mathrm{Hp}$ ratio; a biconcave deformity is characterized by a low $\mathrm{Hm} / \mathrm{Hp}$ ratio; and a compression deformity is characterized by a low Hp/Dap ratio [14].
The present study attempted to assess the effect of sportsrelated loading on the remodeling of the twelfth thoracic vertebra and the five lumbar vertebrae in basketball players, as predictive markers for future injury or lower back pain.

\section{Material and Methods}

\section{Participants}

For this study, 20 basketball players (mean age $=20.90$, standard deviation $=2.84$ ) with and without symptoms of lumbar pain underwent a case history and a physical examination. The participants were classified in two groups: senior players, with $\geq 5$ years of experience; and junior players, with $<5$ years of experience. The two groups were matched for sex and age. All participants provided informed consent before commencing the experiment. Players who underwent previous operation in their spine, and players with history of smoking habit were excluded from the study. The study was approved by the Institutional Review Board of our university.

\section{Measures}

The pain description for each player was identified by a selfreported questionnaire and a physical examination conducted by an orthopedic specialist. The age, body height, mass, and the body mass index (BMI) of all the subjects were documented. No participant was medicated during the study. A dedicated $1.5 \mathrm{~T}$ MRI was performed by technicians for lateral views of the lumbar spine and sacral region of all participants (Figure 1).

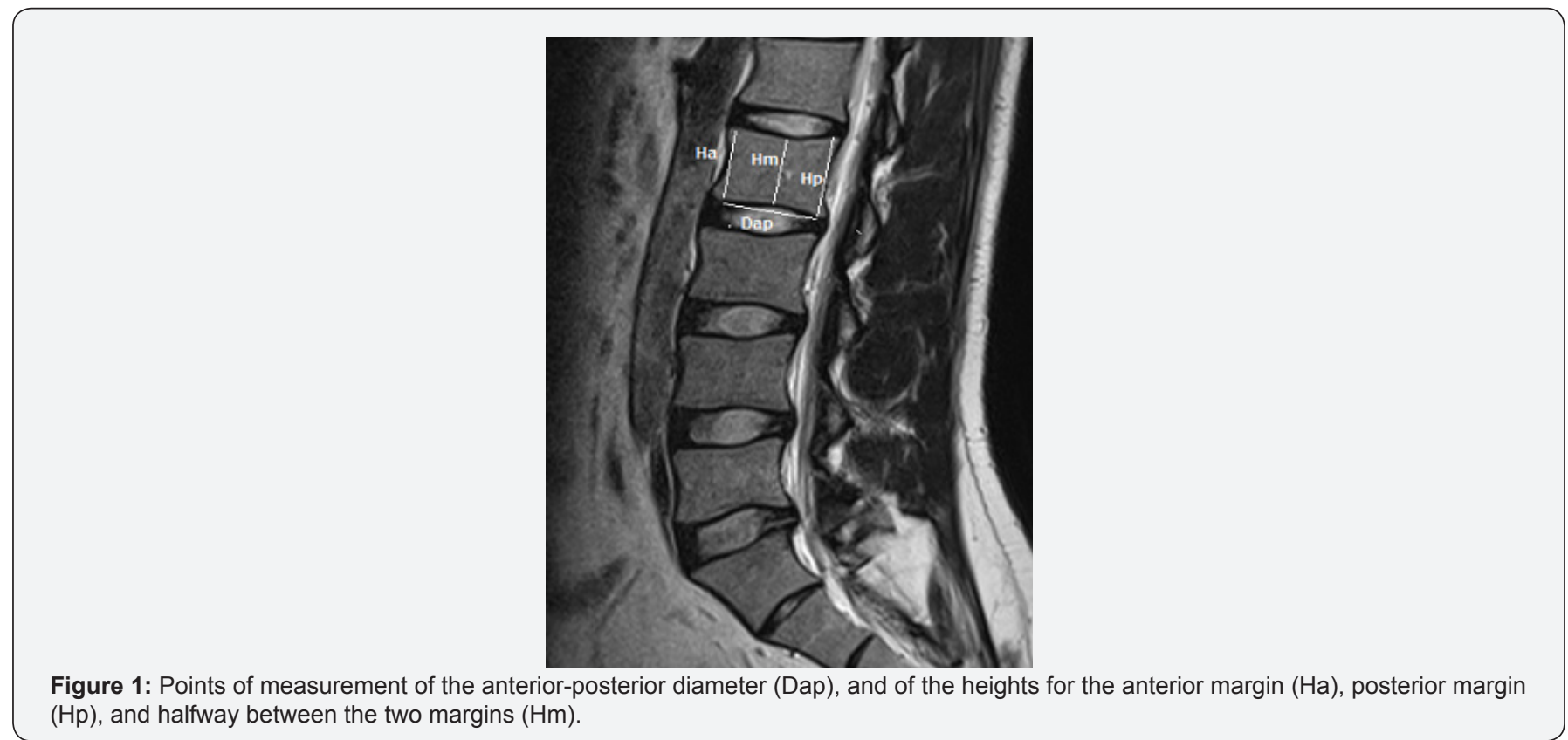

The whole body of the vertebra was estimated on each image using Kinovea version 0.8.15 (Kinovea, France) and syngo fast View version 1.0 (Siemens, Munich, Germany), and all measurements were performed blinded to any other information or measurement regarding the subject.

\section{Procedures}

After completing the imaging process, geometric variables were selected using the two referred software, including: lumbar body index (Hp/Ha ratio) (Smith et al., 1996), anterior wedge deformity ( $\mathrm{Ha} / \mathrm{Hp}$ ratio), biconcave deformity ( $\mathrm{Hm} / \mathrm{Hp}$ ratio), and compression deformity (Hp/Dap ratio) [14]. 


\section{Statistical analysis}

Data of outcome variables were tested using independent t-test for differences between the two selected groups. Data analysis was performed using SPSS version 17.0 (IBM, Chicago, Illinois, US), and level of significance was set as 0.05 .

\section{Results}

Our findings showed that, between the senior and junior groups, there were no significant differences regarding age, weight, height, or BMI. This result suggests that these factors did not affect the results of the study.

Table 1: Descriptive statistics of vertebral body measurements at each level of the lumbar spine (T12, L1-L5) in senior and junior basketball players.

\begin{tabular}{|c|c|c|c|c|c|c|c|c|c|c|}
\hline \multirow{2}{*}{ Vertebral Level } & \multirow{2}{*}{ Group } & \multirow{2}{*}{$\mathbf{N}$} & \multicolumn{2}{|c|}{ Lumbar Index } & \multicolumn{2}{|c|}{ Ha/Hp Ratio } & \multicolumn{2}{|c|}{ Hm/Hp Ratio } & \multicolumn{2}{|c|}{ Hp/Dap Ratio } \\
\hline & & & Mean & SD & Mean & SD & Mean & SD & Mean & SD \\
\hline \multirow{2}{*}{$\mathrm{T} 12$} & junior & 10 & 1.112 & 0.045 & 0.89 & 0.035 & 0.914 & 0.036 & 1.044 & 0.078 \\
\hline & senior & 10 & 1.034 & 0.114 & 0.968 & 0.12 & 0.954 & 0.054 & 0.892 & 0.104 \\
\hline \multirow{2}{*}{ L1 } & junior & 10 & 1.102 & 0.043 & 0.91 & 0.024 & 0.896 & 0.041 & 1.082 & 0.032 \\
\hline & senior & 10 & 1.112 & 0.055 & 0.89 & 0.044 & 0.884 & 0.045 & 0.946 & 0.056 \\
\hline \multirow{2}{*}{ L2 } & junior & 10 & 1.056 & 0.046 & 0.94 & 0.042 & 0.872 & 0.034 & 1.088 & 0.05 \\
\hline & senior & 10 & 1.068 & 0.076 & 0.932 & 0.068 & 0.868 & 0.021 & 0.956 & 0.059 \\
\hline \multirow{2}{*}{ L3 } & junior & 10 & 1.076 & 0.035 & 0.926 & 0.027 & 0.85 & 0.018 & 1.078 & 0.091 \\
\hline & senior & 10 & 1.036 & 0.063 & 0.966 & 0.062 & 0.814 & 0.041 & 0.954 & 0.076 \\
\hline \multirow{2}{*}{ L4 } & junior & 10 & 1.01 & 0.04 & 0.982 & 0.043 & 0.846 & 0.046 & 0.972 & 0.069 \\
\hline & senior & 10 & 0.996 & 0.059 & 0.998 & 0.059 & 0.816 & 0.074 & 0.924 & 0.073 \\
\hline \multirow{2}{*}{ L5 } & junior & 10 & 0.894 & 0.046 & 1.112 & 0.058 & 0.834 & 0.06 & 0.872 & 0.061 \\
\hline & senior & 10 & 0.862 & 0.012 & 1.15 & 0.017 & 0.848 & 0.04 & 0.838 & 0.074 \\
\hline
\end{tabular}

The height of the vertebral body was measured in three places: at the anterior margin (Ha), at the posterior margin ( $\mathrm{Hp})$, and at halfway between these margins $(\mathrm{Hm})$. Three types of vertebral deformities can be defined based on these heights and on the anterior-posterior diameter (Dap): anterior wedge deformity (low Ha/Hp ratio); biconcave deformity (low Hm/Hp ratio); and compression deformity (low Hp/Dap ratio). SD: standard deviation; N: number of participants in the group.

Table 2: Comparison between senior and junior basketball players with respect to vertebral body measurements at each level of the lumbar spine (T12, L1-L5).

\begin{tabular}{|c|c|c|c|c|c|c|c|c|}
\hline \multirow{2}{*}{ Vertebral Level } & \multicolumn{2}{|c|}{ Lumbar Index } & \multicolumn{2}{c|}{ Ha/Hp Ratio } & \multicolumn{2}{c|}{ Hm/Hp Ratio } & \multicolumn{2}{c|}{ Hp/Dap Ratio } \\
\cline { 2 - 9 } & t- value & $\mathbf{P}$ & t- value & $\mathbf{P}$ & t- value & P & t- value & P \\
\hline T12 & 1.99 & 0.06 & -1.96 & 0.07 & -1.94 & 0.68 & 3.67 & 0.002 \\
\hline L1 & -0.44 & 0.65 & 1.25 & 0.22 & 0.62 & 0.54 & 6.65 & $<0.001$ \\
\hline L2 & -0.42 & 0.67 & 0.31 & 0.75 & 0.3 & 0.76 & 5.34 & $<0.001$ \\
\hline L3 & 1.73 & 0.1 & -1.86 & 0.08 & 2.47 & 0.02 & 3.28 & 0.004 \\
\hline L4 & 0.62 & 0.54 & -0.68 & 0.5 & 1.08 & 0.29 & 1.5 & 0.15 \\
\hline L5 & 2.1 & 0.06 & -1.96 & 0.07 & -0.6 & 0.55 & 1.1 & 0.28 \\
\hline
\end{tabular}

The height of the vertebral body was measured in three places: at the anterior margin ( $\mathrm{Ha})$, at the posterior margin ( $\mathrm{Hp})$, and at halfway between these margins $(\mathrm{Hm})$. Three types of vertebral deformities can be defined based on these heights and on the anterior-posterior diameter (Dap): anterior wedge deformity (low $\mathrm{Ha} / \mathrm{Hp}$ ratio); biconcave deformity (low $\mathrm{Hm} / \mathrm{Hp}$ ratio); and compression deformity (low $\mathrm{Hp} / \mathrm{Dap}$ ratio). P-values lower than 0.05 were considered significant.

The ratios, for both groups, of $\mathrm{Hm} / \mathrm{Hp}, \mathrm{Ha} / \mathrm{Hp}$ ratio, and $\mathrm{Hp} /$ Dap for each level of the lumbar spine, and for the $12^{\text {th }}$ thoracic vertebral body are shown in Table 1. Further, we observed significant differences between the senior and junior groups regarding $\mathrm{Hp} /$ Dap ratio at the spine levels $\mathrm{T} 12(\mathrm{t}=3.67, \mathrm{p}=$ 0.002), L1 ( $\mathrm{t}=6.65, \mathrm{p} \leq 0.001), \mathrm{L} 2$ (5.34, $\mathrm{p} \leq 0.001)$, and L3 ( $\mathrm{t}$ $=3.28, p=0.004$ ) (Table 2), revealing that senior basketball players exhibit greater compression deformity in these levels of the spine when compared to junior basketball players.

Accordingly, we also observed greater compression deformities in the L4 and L5 levels of the senior basketball players when compared with junior players; however, those results were not statistically significant.
Moreover, the senior basketball players had significantly higher $\mathrm{Hm} / \mathrm{Hp}$ ratio at $\mathrm{L} 3$ level $(\mathrm{t}=2.47, \mathrm{p}=0.02)$ when compared with the junior basketball players, revealing that senior basketball players exhibit greater biconcave deformities in L3 when compared to junior basketball players.

On MRI examination, no significant difference between the two groups was observed regarding anterior wedge deformity, or lumbar body index.

\section{Discussion}

High level sports participation in adolescents and young adults is associated with a greater incidence of low back pain and structural abnormalities, as revealed in imaging studies [15]. 
Back pain has significant effects on the athletes' performance and is estimated to occur in $1.1 \%$ to $30 \%$ of athletes, with some variation depending on the type of sports activity. Among basketball players, low back pain is a common problem [16-20]. Pain in the spine is often difficult to diagnose. Loading appears to play an important role in the development of radiographic changes of the lumbar spine, and one factor that can dramatically affect the load on the lumbar spine is body position [21]. In the present study, we used MRI, which is considered the most accurate imaging modality for assessing the spine [22]. However, it is important to note that abnormal imaging findings are not always related to the source of the pain, as pathology can exist without pain, and vice versa. In the present study, we assessed degenerative changes related to vertebral body size and shape, which may be considered predictive markers for future lower back pain or injury.

Basketball is popular worldwide and creates unique physiological and physical demands on the players. For example, playing and dribbling the ball are usually executed in a position of spinal flexion, Repetitive jumping, landing from height, and abrupt changes of direction create significant forces acting on the spine. Such repetitive loading can create microscopic damage within a material or tissue, which gradually builds up until gross failure occurs. In living tissues, the process of damage accumulation is opposed by the process of adaptive remodeling $[1,14]$. According to Alexander [3], the type of injury that occurs in the lumbar spine, which is under significant stress in basketball players, is dependent on the direction, magnitude, and the point of application of the forces in the spine. Ruyssen-Witrand et al. [23] proposed that vertebral size should be considered a potential independent risk factor for vertebral fracture.

Several studies have compared lumbar spine abnormalities of elite athletes with those in non-athletic groups with respect to various sports such as wrestling, soccer, tennis, track and field, and gymnastics [24-26].

In this study, we focused on two groups with the same sex, range of age, and range of BMI, but with different experience with respect to playing basketball. We hypothesized that, independently of other factors, more years of playing in basketball-specific body positions and acceleration motions may cause more abnormalities in the lumbar spine. Indeed, we found that the vertebrae T12, L1, L2, and L3 showed a significantly higher compression deformity in senior basketball players. Likewise, L3 had more biconcave deformities (lower Hm/Hp ratio) in senior basketball players. Thus, playing basketball for more years appears to cause more loading on the lumbar spine, and deformity of the vertebral body.

Our result suggests that, in basketball players, T12 and L1-L3 are at higher risk of degenerative deformities and fractures, as they may be affected by compression and biconcave deformities to a higher extent. Schmitt et al. [26] reported that the concavity index at all levels of the lumbar spine was similar in different groups of track and field athletes. On the other hand, Reilly \& Seaton [27] observed an average spinal shrinkage rate of $0.4 \mathrm{~mm} /$ min in players dribbling a hockey ball. Predisposing factors in basketball include repetitive spinal flexion, extension, twisting, and loading. Poor development of abdominal musculature in conjunction with strong paraspinal muscles may increase the stress on the lumbar spine during hyperextension, while repetitive jumping and changing of direction create significant forces throughout the spine [1]. In basketball, athletes must bend and rotate their bodies. The specific patterns of loading experienced by the basketball players during dribbling, frequent flexion, and hyperextension may explain the higher rate of radiographic changes we found for the vertebral body of T12, L1, L2, and L3 in more experienced players.

No other significant differences were observed in our MRI examination of the lumbar spine with respect to lumbar index at any level, or compression and biconcave deformity of vertebrae L4 and L5. We did find slight differences with respect to anterior wedge deformity, but this observation did not reach statistical significance, and thus requires more attention before it can be hypothesized as a risk factor for stress fractures.

The present study is limited due to its small population sample, and the fact that it did not account for factors like diet, quality of sleep, or the physical and mental condition of the participants.

\section{Conclusion}

In this study, we focused on loading on the lumbar spine caused by basketball-specific body positions, which may translate into vertebral deformities and thus increase the risk of pain and spinal injury, and ultimately prevent the player from participating in sport events. Athletes with minor fractures in the lumbar vertebral body but without neurologic involvement may be considered to return to the sport competition, but under the supervision of the coach and physician; however, they should be made aware of the risks of future injury caused by the deformities. Coaches and athletes may consider these risk factors and apply proper training and conditioning to avoid the development of vertebral body deformities.

In general, athletes and coaches in sports that have an increased risk of lumbar spine injury should be educated in preventive techniques. Specific sport training may be considered to support this part of the spine, with the understanding that significant forces are transferred to the lumbar vertebrae, and with knowledge of the sport-specific deformation likely to occur at various spinal levels.

\section{Acknowledgements}

The authors would like to thank the athletes who participated in this study, as well as the employees of the Orthopedics Department and the technicians of the MRI Centre at our hospital for their support with data collection. 


\section{References}

1. Cook J, Khan K (2003) Spine and pelvis. In: McKeag DB (Ed.), Handbook of Sports Medicine and Science: Basketball. ( $1^{\text {st }}$ edn), London: Blackwell Science Ltd, UK, pp. 164-172.

2. Smith RM, Loschner C (2002) Biomechanics feedback for rowing. J Sports Sci 20(10): 783-791.

3. Alexander MJ (1985) Biomechanical aspects of lumbar spine injuries in athletes: a review. Can J Appl Sport Sci 10(1): 1-20.

4. d'Hemecourt PA, Hresko MT (2012) Spinal deformity in young athletes. Clin Sports Med 31(3): 441-451.

5. Tertti M, Paajanen H, Kujala UM, Alanen A, Salmi TT, et al. (1990) Disc degeneration in young gymnasts. A magnetic resonance imaging study. Am J Sports Med 18(2): 206-208.

6. Videman T, Nurminen M, Troup JDG (1990) Lumbar spinal pathology in cadaveric material in relation to history of back pain, occupation, and physical loading. Spine 15(8): 728-740.

7. Kazarian LE (1975) Creep characteristics of the human spinal column Orthop Clin North Am 6(1): 3-18.

8. Crock HV (1986) Internal disc disruption. A challenge to disc prolapse fifty years on. Spine (Phila Pa 1976) 11(6): 650-653.

9. Adams MA, Freeman BJ, Morrison HP, Nelson IW, Dolan P (2000) Mechanical initiation of intervertebral disc degeneration. Spine (Phila Pa 1976) 25(13): 1625-1636

10. Holm S, Holm AK, Ekström L, Karladani A, Hansson T (2004) Experimental disc degeneration due to endplate injury. J Spinal Disord Tech 17(1): 64-71.

11. Adams MA, Hutton WC (1982) Prolapsed intervertebral disc. A hyperflexion injury 1981 Volvo Award in Basic Science. Spine (Phila Pa 1976) 7(3): 184-191.

12. Boocock MG, Reilly T, Linge K, Troup JDG (1986) Fine Measurement of Stature for Studying Spinal Loading. In: Reilly T, Watkins J, Borms J (Eds.), Kinanthropometry III. Spon (Verlag), London, UK, pp. 98-103.

13. Ogurkowska MB (2007) Pathological changes in lumbar-sacral intervertebral discs in professional rowers. Biol Sport 24(4): 375-388.

14. Adams MA, Bogduk N, Burton K, Dolan P (2013) The Biomechanics of Back Pain. ( $3^{\text {rd }}$ edn), Edinburgh: Churchill Livingstone, UK.
15. Videman T, Sarna S, Battié MC, Koskinen S, Gill K, et al. (1995) The longterm effects of physical loading and exercise lifestyles on back-related symptoms, disability, and spinal pathology among men. Spine (Phila Pa 1976) 20(6): 699-709.

16. Hubbard DD (1974) Injuries of the spine in children and adolescents. Clin Orthop Relat Res 100: 56-65.

17. Micheli LJ (1965) Back injuries in gymnastics. Clin Sports Med 4(1): 85-93.

18. Dreisinger TE, Nelson B (1996) Management of back pain in athletes. Sports Med 21(4): 313-320.

19. Frank CB (1996) Ligament healing: current knowledge and clinical applications. J Am Acad Orthop Surg 4(1): 74-83.

20. McKay GD, Goldie PA, Payne WR, Oakes BW, Watson LF (2001) A prospective study of injuries in basketball: a total profile and comparison by gender and standard of competition. J Sci Med Sport 4(2): 196-211.

21. Dolan P, Earley M, Adams MA (1994) Bending and compressive stresses acting on the lumbar spine during lifting activities. J Biomech 27(10): 1237-1248.

22. Crewe H, Elliott B, Couanis G, Campbell A, Alderson J (2012) The lumbar spine of the young cricket fast bowler: an MRI study. J Sci Med Sport 15(3): 190-194.

23. Ruyssen-Witrand A, Gossec L, Kolta S, Dougados M, Roux C (2007) Vertebral dimensions as risk factor of vertebral fracture in osteoporotic patients: a systematic literature review. Osteoporos Int 18(9): 12711278 .

24. Jones DM, Tearse DS, el-Khoury GY, Kathol MH, Brandser EA (1999) Radiographic abnormalities of the lumbar spine in college football players. A comparative analysis. Am J Sports Med 27(3): 335-338.

25. Lundin O, Hellström M, Nilsson I, Swärd L (2001) Back pain and radiological changes in the thoraco-lumbar spine of athletes. A longterm follow-up. Scand J Med Sci Sports 11(2): 103-109.

26. Schmitt H, Dubljanin E, Schneider S, Schiltenwolf M (2004) Radiographic changes in the lumbar spine in former elite athletes. Spine (Phila Pa 1976) 29(22): 2554-2559.

27. Reilly T, Seaton A (1990) Physiological strain unique to field hockey. J Sports Med Phys Fitness 30(2): 142-146.

\section{Your next submission with Juniper Publishers will reach you the below assets}

- Quality Editorial service

- Swift Peer Review

- Reprints availability

- E-prints Service

- Manuscript Podcast for convenient understanding

- Global attainment for your research

- Manuscript accessibility in different formats

( Pdf, E-pub, Full Text, Audio)

- Unceasing customer service

Track the below URL for one-step submission

https://juniperpublishers.com/online-submission.php 